\title{
Improving Health System in Egypt: Perspectives of Physicians
}

\author{
Nesreen M. Kamal Elden*, Hoda I. Ibrahim Rizk*, Ghada Wahby* \\ * Department of Public Health and community medicine, Faculty of Medicine, Cairo \\ University, Egypt \\ Received 9-7-2015, accepted 25-8-2015
}

\begin{abstract}
Introduction: There are well-identified shortcomings in the health system at the policy level. However, there is no adequate information at the implementation level, especially at the level of health services providers. Objectives: The goal of the study is to improve the health system in Egypt through utilizing information derived from the perspectives of the health service providers towards the health system. Methodology: a health system research exploratory study was conducted in Cairo governorate. A convenient sample of 225 physicians, working in $\mathrm{MOH}$ and private facilities, were included. Results: More than half of physicians agree that there are shortages in the health system resources: $(70.6 \%),(53.7 \%)$ and $(25 \%)$ in private, secondary health care (SHC) and primary health care $(\mathrm{PHC})$, respectively, $\mathrm{P}=0.04$. $(71.2 \%)$ and $(49.7 \%)$ say there is bias in human recruitment and no clear job description, respectively, with no significant difference by place of work. Moreover, about $(66.2 \%)$ and $(57.6 \%)$ of all participants physicians, respectively, say that there is neither supervision for their performance nor records with performance indicators. Subsequently, $(58.9 \%)$ of the physicians see that the health status of the Egyptian is:"unaccepted". Conclusion and recommendations: The health care system still faces multiple challenges in improving health status of all Egyptians. There are shortages in health care resources, at different levels of care. Physicians see that organizational structure and management of the system still need reform. The distribution and quality of human resources need to be improved, equally. Physicians were aware of system problems'. For that, their opinions should guide the policy makers for setting effective strategies to improve the health system
\end{abstract}

Keywords: Health system, Physicians, Management

*corresponding author, Email: drhoda2000@yahoo.com (Hoda Ibrahim Ibrahim Rizk)

\section{Introduction}

Egypt after the January 25, 2011 revolution started dramatic actions for improving different systems in the country, including the health system. Many of the published reports had identified the challenges that confront the health system to achieve the goal of the Ministry of Health and Population (MOHP) of improving health of all citizens. Those shortcomings are identified at the policy level and include: Inadequate expenditure on health: The overall spending on health represents $3.7 \%$ of the GDP. MOHP budget forms $3.3 \%$ of the governmental budget (2000/2001) and MOHP expenditure per capita per year was LE 56.7 in year $2001^{(1)}$. Inefficient health 
insurance system: The profile of Health Insurance (HI) program in Egypt 2005 regarding coverage and eligibility of $\mathrm{HI}$ beneficiaries indicate that about $50 \%$ of the population are covered with health insurance and include: school children (24\%), U5 children (13\%), workers $(10 \%)$ and pensioners $(3 \%)^{(2)}$. Inefficient management of the health system at MOHP level is due to the centralized control, extensive infrastructure, and governmental responsibility for health care for all individuals and extensive governmental involvement in the pharmaceutical sector (3). Complex organizational structure of the health system: There are multiple public and private sources of finance and delivery of health care and limited governmental oversight of the private sector (2) Inefficient health services delivery: Shortcomings in human resources include low capacities and skills, mal-distribution of physicians across geographic regions and specialties and insufficient salaries and incentives. Additionally, the health facilities' infrastructure (building, furniture and maintenance) is deteriorating (4). Reliance on vertical-donor-supported primary health care (PHC) programs: vertical programs as family planning (FP), maternal and child health (MCH) have shortcomings related to being fragmented with lack of coordination at the planning and implementation levels and negligence of necessary support system as district hospital/referral services (4). Disease Burden: Due to demographic and epidemiologic and nutrition transition, Egypt has a very long list of health problems: high rate of population growth, endemic and infectious diseases, high maternal and child morbidity and mortality, chronic/non-communicable diseases ${ }^{(5)}$.
This pattern of disease burden requires a strong health system that deal with prevention/communication for behavior change and secondary care programs. In addition, shortage in Basic public services: unsatisfactory environmental indicators related to housing, slums, shortage of safe water, sewage disposal, and air pollution contribute in increasing morbidity and mortality ${ }^{(2)}$.

In response to the shortcomings of the health system, Egypt launched the Health Sector Reform Program (HSRP) in 1997: Egypt HSRP is a program of transformation between 1997 and 2020 with an overall goal of shifting the focus of health care from reliance on vertical programs and inpatient care to a more integrated and less costly, quality, universally accessible and sustainable primary health care model.

The HSRP has 4 main objectives ${ }^{(6)}$ :

1. Ensuring universal coverage with Basic Health Services

2. Improved organization and management of the health system

3. Improved health services delivery

4. Improved the pharmaceutical system

Despite the launching of HSRP many years ago, there are still many shortcomings in the health system, with no adequate information at the implementation level, especially at the level of health services providers. Physicians' perspectives at the health delivery level are essential for better understanding of the health system's challenges

\section{Objectives}

General Objective 
Improve the performance of the health system in Egypt through identification system's challenges.

\section{Specific Objectives:}

Explore the perspective of physicians towards the following:

1. Resources in health facilities: manpower, medications, equipment and infrastructure

2. Management of resources: Organizational structure and staffing, job description, training, supervision, monitoring, controlling and use of management information system

3. Effect of health services on the community regarding health status

\section{Methodology}

\section{Study Design}

The study is health system-exploratory pilot study. The study is cross-sectional survey study that includes data collection from physicians working in $\mathrm{MOH}$ or private health facilities in Cairo governorate.

\section{Study Setting}

The study was conducted in three randomly selected health care facilities within the catchment area of Cairo University: one primary health care (PHC) (Zeinhom Health Care Center), one secondary health care (SHC) (El Mounira General Hospital) and one private hospital (ElHekma)

\section{Sample Size and Sampling Technique}

A convenient sample of physicians who practiced medicine in different type of health facilities, within catchment area, was included. The facilities were randomly selected from three prepared lists for the primary, secondary and private facilities within catchment area of Cairo University. At the confidence level of $95 \%$, percent of physicians' satisfaction from the health care system $50 \%$ and $\alpha=0.05$, minimum sample size was calculated to be 217 . The data was collected by medical students who participated in a training course on health system research. The total trained personnel, who were 20 students, collected data from 225 physicians.

\section{Data Collection:}

A self administered questionnaire containing questions that delineate information about the health system components:

- Resources in health facilities: (17 items)

- Management of resources: (32 items)

- Effect of health services on the community regarding health status ( one item)

Questionnaire was tested on 10 physicians, and required modifications were done.

\section{Data Quality Check}

The completed format was revised by assigned members from each team of data collectors. Each team reviewed the completed forms of the other team. After data entry, frequencies tests were conducted to identify any error in data collection and data entry.

Data Analysis Plan 
Pre coded data were entered on Microsoft Office Excel Program for Windows, 2007. Data were then transferred to the Statistical Package of Social Science, version17 (SPSS.17). Simple statistical methods were used. The perspectives of physicians towards: resources of the health system and management of resources were identified as: agree-agree very much and don't agree. The scores have been scaled in a positive direction, with a score range scaled ( 0 for don't agree- 1 for agree and 2 for agree very much). A cut off point was determined based on the mean value of total responses 'scores for each item. Responses' scores above the mean value were considered as "agree" and, those below the mean value were considered as "don't agree". Subsequently, percent of physicians' agreement was calculated from all responses. The $\mathrm{P}$ value $\leq 0.05$ was used as the cut-off level for statistical significance. Chi-square was used to detect associations between categorical variables.

The views of physicians towards Excellence of Egyptian health status was described as percentage from total into: Unaccepted- accepted-good-very good and excellent.

\section{Ethical Considerations}

There is an approval by Faculty of Medicine -Cairo University to conduct the study. The team of data collectors introduced themselves to the manager of each facility. They described the objectives of the study and got their verbal approval to conduct the research in their facilities. The data was collected after getting verbal consent from the participants. The research team had the policy of storing the completed questionnaire forms. The policy includes: data entry using code numbers rather than names. After completing data entry, the format had been kept in the Public Health Department. After dissemination of the research findings, the completed forms will be destroyed by paper destruction machine.

\section{Limitations of the Study}

The study is a pilot study that includes physicians from Cairo governorate, and therefore, the study findings could not be generalized to all Egypt. In addition, the physicians 'place of work were different: primary, secondary and private. However, all physicians are working within the same system and their opinions could reflect the current situation of the health system in Egypt. This was an exploratory pilot study for the physicians' perspectives towards health system, at the health delivery level. Further studies are needed to explore physicians' perspectives at the administrative or the central level.

\section{Results}

Table 1 presents the general characteristics of the physicians: More than half of the physicians $(53.3 \%)$ were male. About $60 \%$ of the physicians were graduated $\leq$ year 2000. (20.8\%) and $(60.8 \%)$ worked at a primary health care and secondary care, respectively. About $18 \%$ of the physicians provide private health care services. About $19 \%$ of the physicians practiced Internal Medicine. Almost equal number of physicians (13.3\%) practiced General Surgery and Pediatrics. (11.5\%) physicians were gynecologist. (3.1\%) of physicians were 
practicing Family Medicine, equal to ENT and Orthopedics physicians.

Table (2) illustrates the views of physicians towards shortcomings in some of the resources in the health system by place of work. More than $(53 \%)$ of the physicians agree that there are shortages in resources of health system: $(70.6 \%),(53.7 \%)$ and $(25 \%)$ from private, $\mathrm{SHC}$ and $\mathrm{PHC}$, respectively, $\mathrm{P}=0.04$.

As regards health facilities, more than $61 \%$ of physicians working in the private facility and $58 \%$ of physicians in SHC say there are shortcomings in health care facilities versus about $26 \%$ of those in $\mathrm{PHC}$ and this difference is statistically significant, $\mathrm{P}=0.03$. (68.5\%) and $(57 \%)$ of physicians, respectively, say that neither the site nor the design of the building is appropriate. (58.9\%), $(61.9 \%)$, (39.1) of all the physicians agree that there is no maintenance of health care buildings, neither access to electricity nor to safe water supply. These problems are significantly higher in the private facility than in PHC. About half of the physicians see shortage in number of nurses and about $70 \%$ of them say that the nurses' training is inadequate. These problems are significantly higher in the private and SHC. (72.7\%), (71.1\%) and (63.3\%) of the physicians that works at SHC, private and $\mathrm{PHC}$, respectively, agree that there is shortage in some drugs. In addition, (47.1\%) of physicians agree that the drug list is always constant.

Table 3 presents the views of physicians towards management of health system according to their place of work. As regards health care planning, (19.3\%) and one quarter physicians don't agree that $\mathrm{MOH}$ has a clear plan, neither at the central level nor at the local level respectively, with no significant difference by place of work. Less than $40 \%$ of all physicians see that decisions are taken on scientific base. In addition, more than half of physicians say that there is no training on organizational management.

There are huge problems in the organizational structure of the $\mathrm{MOH}$, according to the physicians 'perspectives. More than $70 \%$ of physicians agree on the presence of bias in human resources recruitment: $(78.6 \%)$ in PHC, $(72.3 \%)$ in SHC and $(62.5 \%)$ in private facility, with no significant difference. Moreover, about 1 from every 2 physicians says that they don't have job description, with no significant difference by place of work. Although, about $47 \%$ of physicians agree that there is inflation in the organizational structure, an equal percent of them agree that there is no staff in some positions.

Less than one fifth of the physicians agree on the presence of continuous training opportunities, within health care system. At the same time, $(29.4 \%)$ from the private, (26.3\%) from PHC versus (13.8\%) from the SHC of the physicians mentioned the availability of training opportunities outside Egypt, respectively, $\mathrm{P}=0.01$. (38.2\%) of them agree that scientific evidence is the base of service delivery. Less than quarter of physicians agree that they receive license every three years.

Less than one third of physicians agree on the presence of supervision, within health care system, with no significant difference by place of work. (26\%) of them agree that the supervision is always supportive: $(41.4 \%),(27.5 \%)$ and $(8.3 \%)$ in $\mathrm{PHC}, \mathrm{SHC}$ and private, respectively, 
$\mathrm{P}=0.008$. (22.8\%) of the respondents agree on the presence of any control on physician who refers patients to their private practice, with no significant difference by place of work. (57.6\%) and $(72.8 \%)$ of the respondents don't agree that there is neither monthly records to monitor performance nor that the information system is used during decision making process.

Figure (1) shows perspectives of physicians toward the health status of the Egyptians, which were as follows: $(58.9 \%)$ of the physicians say that the Egyptian health status is:"unaccepted", (28\%) perceive it as "accepted". (10.7\%) describe the health status of the Egyptians to be "good". Only (2.5\%) of the physicians describe the Egyptian health status as "very good or excellent".

\section{Discussion}

Despite the information about the shortcomings of the health system is available at the policy level, and the specific interventions through the Health Sector Reform, there is no enough information at the peripheral level, especially the perspectives of the physicians to the current health system.

Physician is a production factor in the health system and has an essential impact on the efficiency and effectiveness of the health care delivery system. For that, this study was conducted among physicians, with the intention of eliciting their professional opinion towards health system.

Egypt has an extensive network of facilities with $95 \%$ of Egyptians living within $5 \mathrm{~km}$ of a health facility ${ }^{(7)}$. HSRP ensures that the health facility location and accommodations should fulfill specific standards within the accreditation system ${ }^{(8)}$. However, more than $60 \%$ physicians in PHC believe that the site of health facilities isn't appropriate to population distribution. This may be due to inequity in the access and the utilization of the system ${ }^{(7)}$.

More than half of the physicians say there are shortages in some of health care resources and the problem is significantly higher among private $(70.6 \%)$ and SHC $(53.7 \%)$ than in the PHC $(25 \%)$. There is a serious shortage of qualified nurses, especially graduate nurses; a complete lack of well-qualified midwives and a shortage of paramedical staff. Diploma nurses have a quite low level of qualification and training. Although, there has been a 56\% year-onyear increase in graduate nurse who are registered with the $\mathrm{MOH}{ }^{(7)},(55.5 \%)$ and $(70.7 \%)$ of SHC physicians versus $(11.1 \%)$ and $(44.5 \%)$ of PHC physicians agree that there is still shortage in nurse and inadequate nurses' training, respectively. These differences are statistically significant.

The essential drug list for primary care level was developed by HSRP and should be updated annually ${ }^{(7)}$. However, more than $39.3 \%$ of the respondents from PHC, in the current study, see that the drug list is always constant. HSRP policies and regulations include the availability of the essential drug list where medications should be available at both the family health units and centers in a continuous basis ${ }^{(9)}$. Although, the availability of drugs and medical supplies, is a top priority to maintain the sustainability of high quality of services for HSRP, $(72.7 \%)$ and $(63.3 \%)$ of the physicians at SHC and PHC, respectively, complain of drug shortage. Lack of management skill and poor training in managerial skill is one of the 
main challenges for the health system ${ }^{(10,}$ 11). In this study, more than half of physicians mentioned that there is no training on organizational management.

Conditions for employment offered by the MOHP are determined by the Ministry of Finance in negotiation with Central Agency for Organization and Administration. The human resource management function in the public sector is limited by a number of constraints. The MOHP lacks a national human resource plan. Although, the MOHP has a computerized personnel database, it is not used for planning or for projecting future needs. The MOHP does not refer to job descriptions in recruitment ${ }^{(7,12)}$. For that, $(71.2 \%)$ of all physicians believe that there is bias in human resources recruitment and about half of them agree that there is no job description, with no significant difference by place of work.

Strategies have to be developed to employ the physician factor efficiently in health care delivery system. A proactive management of human resources has to find its place into health care management, to ensure keeping highly educated workforce from leaving their country ${ }^{(13)}$

The MOHP decision -making process is mostly subjective and rarely information based because the management information systems are still underdeveloped $^{(\mathbf{1 1})}$ : less than $40 \%$ of physicians think that decision making process is done on scientific base. Medical education must take a leading role in disseminating new information and in teaching future physicians to evaluate and contribute to the evidence that advances clinical care worldwide (14). However, MOHP does not control the curriculum of medical schools ${ }^{(7)}$. For that, about $38 \%$ of the respondents say that the service delivery is done by trial and error and not scientific base.

Continuing education remains an individual choice among physicians rather than a requirement. This has significant implications on improving the knowledge and skills of the health workforce. In the current study, more than $80 \%$ of physicians mentioned lack of continuous training opportunities.

Supervision of the health workforce is in general limited. Procedures such as medical audit to identify weaknesses are rarely applied ${ }^{(7,15)}$. The health facility staff is supervised by three supervision teams: family health fund, Governorate technical support team (TST), and District provider organization (DPO). According to the job description, the family health units/centers (FHU/FHC) director and Head Nurse supervise the FHU/FHC staff and provide mentoring and in-service education. The supervisors from FHF and DPO focus on the health facility achievements onmonthly basis to set the incentives. Supervision is looking at records, general/common items to all service (8). However, only (48.3\%) of the physicians in PHC agree that there is supervision.

The salary scale, within public system, is low and is considered a major reason why doctors engage, also, in private practice. Physicians earn over $80 \%$ of their income from their private work. They often continue to keep their positions in the public sector along with their private practice ${ }^{(7)}$. Although, the lack of clear delineation between physicians' public and private practice results in a loss of discipline among physicians, less than quarter of the respondents say there is any control on 
them, with no significant difference by place of work.

Caring for patients with acute and chronic problems over time and managing preventive services for populations requires working in wellorganized systems and supported by information technology ${ }^{(16,17)}$. However, $72.8 \%$ of the respondents say that information system isn't used in decision making.

A standard evaluation sheet is used for reviewing performance of all employees. The performance review in the public sector does not necessarily relate to promotion, which renders its usage rather limited. For that, more than $57 \%$ of physicians mentioned that there are no monthly records with performance indicators.

In a previous Egyptian study in which respondents were asked to self-rate their health as Excellent, Very Good, Good, Satisfactory and Poor: Overall $9.72 \%$ of the sample felt their health status was either excellent or very good, slightly over $38.33 \%$ considered themselves to be in good health, $32.43 \%$ felt their health was satisfactory, and $19.47 \%$ considered themselves to be in poor health (18) In this study, the Egyptian health status was described, by the physicians, as follows: (58.9\%) believe it is unaccepted versus $(2.5 \%)$ who describe it as either excellent or very good. (28\%) of the respondents consider the Egyptians in an accepted health status. (10.7\%) say that the Egyptian health status is good.

\section{Conclusion}

and

\section{Recommendations:}

Although the HSRP had been launched many years ago, the health care system still faces multiple challenges in achieving its primary goal: improving health status of all the Egyptians. There are shortages in health care resources at almost all level of care. Physicians, at the service delivery level, see that organizational structure and management of the system still need reform. The distribution and quality of human resources needs to be improved, equally. The physicians proved to be aware of the problems of the health care system. For that, their opinions should guide the policy makers for setting effective strategies to improve the health system. They should be given the opportunity, at the implementation level, to take the lead to find solutions for fixing problems and make effect change.

\section{Conflict of interest}

There is no conflict of interest

\section{Acknowledgments}

The authors would like to thank the students who participate in data collection and the physician participants

\section{References}

1) MOHP: Egypt Health System Profile report, HSRP, October 2005

2) Faiad S.: National Health Insurance: December 2005. www.al-ahaly.com accessed in April 2015

3) MOHP and Central Department for Technical Support and Projects: Family Health Fund and Contracting Strategy (Chapter 6): Family Health Facility Implementation Manual. Version 2, May 2004. https://www.openknowledge.worldbank.org/bits tream/handle/10986/14355/411970EG0Healt1ve r0P07631901PUBLIC1.pdf? sequence $=1$

Accessed in April 2015 
4) El-Shafie M: Linking Reproductive Health and Health Reform. CDC Annual Conference, December 19, 2004

5) Galal O M: The nutrition transition in Egypt: Obesity, under-nutrition and the food consumption context. Public Health Nutrition. 2002; 5 (1A): 141-148

6) MOHP: Egypt Health Sector Analysis and Future Strategies, 2003 version 2: MOHP-Central Department for Technical Support and Projects, www.hsrp.gov.eg

7) WHO: Health System profile Egypt 2006, available at http://app.who.int/medicinedocs/docume nts/s17293e/s17293e.pdf. accessed on April 2015

8) El-Zanaty F: Study on reproductive health impact of family health model pilots in Egypt 2011, Ministry of Health and Population and UNFPA-Egypt 2011 Available at http://egypt.unfpa.org/Images/Publicatio n/2011)1/1828cf97-c4b3-46bb-b5fad845a127ca8f.pdf. Accessed on April 2015

9) MOHP and Central Department for Technical Support and Projects: Essential Drug List (Chapter 4): Family Health Facility Implementation Manual. Version 2, May 2004

10) Saleh WF: Reforming Egypt's health system: is it that simple? BMJ. 2006; 333:859.

11) Abdelkadr A: Egypt Health Care System: Past and future. Available at http://pathology.mcw.edu/wpcontent/Upload/Egypt_Health care_System_Past and Future.pdf. Accessed on April 2015
12) MOHP and Central Department for Technical Support and Projects: Human

Resources, Staff Norms and Job Description (Chapter 2): Family Health Facility Implementation Manual. Version 2. May 2004

13) Janus K, Amelung V, Gaitanides M : German physicians "on strike"Shedding light on the roots of physician dissatisfaction. Health Policy; 2007, 82(3):357-65

14) Landy U, Blodgett $M$ and Darney P: Medical education and family planning: developing future leaders and improving global health. International Journal of Gynecology and Obstetrics 2013,121, S25-S28.

15) MOHP- Sector of Technical Support and Projects - HSRP: District Provider

Organization Guidelines-Summary and Outlines May, 2004 www.hsrp.gov.eg

16) Kahn N B: The Future of Family Medicine: A Collaborative project of the Family Medicine Community. Ann Fam Med. 2004; 2(1): S3-S32.

17) MOHP and Central Department for Technical Support and Projects: Medical

Information System (Chapter 10): Family Health Facility Implementation Manual.

Version 2 May 2004.

18) Nandakumar AK, El-Adawy $M$, Cohen MA: Perception of Health Status and Limitations in Activities of Daily Living among the Egyptian Elderly.1998 Available at https://www.hsph.harvard.edu/ihsg/publi cations//pdf/No-79.PD. Accessed on April 2015 
Table (1) Characteristics of Study Participants

\begin{tabular}{|c|c|c|}
\hline \multicolumn{2}{|l|}{ Characteristics } & $\mathbf{N}(\%)$ \\
\hline \multirow[t]{2}{*}{ Sex } & Male & $120(53.3 \%)$ \\
\hline & Female & $105(46.7 \%)$ \\
\hline \multirow[t]{2}{*}{ Age } & $<40$ & $134(59.6 \%)$ \\
\hline & $\geq 40$ & $91(40.4 \%)$ \\
\hline \multirow[t]{2}{*}{ Year of graduation } & $\leq 2000$ & $79(35.1 \%)$ \\
\hline & $>2000$ & $146(64.9 \%)$ \\
\hline \multirow[t]{3}{*}{ Place of Work } & PHC & $47(20.8 \%)$ \\
\hline & SHC & $137(60.8 \%)$ \\
\hline & Private & $41(18.4 \%)$ \\
\hline \multirow{9}{*}{ Specialty } & Internal Medicine & $43(19.1 \%)$ \\
\hline & General Surgery & $30(13.3 \%)$ \\
\hline & Pediatrics & $30(13.3 \%)$ \\
\hline & Gyna and Obstetrics & $26(11.5 \%)$ \\
\hline & ENT & $7(3.1 \%)$ \\
\hline & Ophthalmology & $2(0.8 \%$ \\
\hline & Orthopedics & $7(3.1 \%)$ \\
\hline & Family Medicine & $7(3.1 \%)$ \\
\hline & Others & $73(32.7 \%)$ \\
\hline Total & & $225(100 \%)$ \\
\hline
\end{tabular}


Table (2) Views of Respondents towards Health System Resources by place of work

\begin{tabular}{|c|c|c|c|c|c|}
\hline \multirow{2}{*}{$\begin{array}{l}\text { Perspectives to resources of health } \\
\text { systems } \\
\text { Shortcomings in health facilities }\end{array}$} & \multicolumn{4}{|c|}{ Agreement } & \multirow{2}{*}{$P$ value } \\
\hline & $\begin{array}{l}\text { PHC } \\
(n=47)\end{array}$ & $\begin{array}{c}\text { SHC } \\
(n=137)\end{array}$ & $\begin{array}{l}\text { Private } \\
(n-41)\end{array}$ & $\begin{array}{c}\text { Total } \\
(n=225)\end{array}$ & \\
\hline $\begin{array}{l}\text { Site of facilities is not appropriate to } \\
\text { population distribution }\end{array}$ & $60.7 \%$ & $66.1 \%$ & $82.9 \%$ & $68.5 \%$ & 0.4 \\
\hline No maintenance to the building & $37.9 \%$ & $59.4 \%$ & $72.5 \%$ & $58.9 \%$ & $0.01^{*}$ \\
\hline $\begin{array}{l}\text { Design of building is not appropriate to } \\
\text { service delivery }\end{array}$ & $35.7 \%$ & $56.7 \%$ & $73.7 \%$ & $57 \%$ & $0.009^{*}$ \\
\hline No electricity & $36 \%$ & $64.3 \%$ & $72.2 \%$ & $61.9 \%$ & $0.01^{*}$ \\
\hline No safe water supply & $15.4 \%$ & $41.7 \%$ & $47.4 \%$ & $39.1 \%$ & $0.02^{*}$ \\
\hline No supervision on drug distribution & $16.7 \%$ & $48 \%$ & $57.1 \%$ & $44.7 \%$ & $0.002 *$ \\
\hline $\begin{array}{l}\text { No relation between type of drug } \\
\text { provided and type of provided health } \\
\text { services }\end{array}$ & $18.5 \%$ & $43.6 \%$ & $39.4 \%$ & $39 \%$ & $0.05^{*}$ \\
\hline $\begin{array}{l}\text { No supervision on maintenance of } \\
\text { equipment }\end{array}$ & $46.4 \%$ & $59.4 \%$ & $66.7 \%$ & $58.9 \%$ & 0.3 \\
\hline $\begin{array}{l}\text { No relation between equipment provided } \\
\text { and type of provided health services }\end{array}$ & $37 \%$ & $47.2 \%$ & $55.6 \%$ & $47.4 \%$ & 0.3 \\
\hline Total & $26.3 \%$ & $58.0 \%$ & $61.5 \%$ & $54 \%$ & 0.03* \\
\hline \multicolumn{6}{|l|}{ Shortcomings in nurse distribution } \\
\hline $\begin{array}{l}\text { Number of nurses in hospitals exceeds } \\
\text { those in PHC }\end{array}$ & $42.3 \%$ & $40.5 \%$ & $39.3 \%$ & $40.6 \%$ & 0.9 \\
\hline $\begin{array}{l}\text { Number of nurses in PHC exceeds those } \\
\text { in hospitals }\end{array}$ & $60.0 \%$ & $63.0 \%$ & $81.5 \%$ & $65.6 \%$ & 0.2 \\
\hline Shortage in number of nurses & $11.1 \%$ & $55.5 \%$ & $59.5 \%$ & $49.7 \%$ & $\leq 0.001^{*}$ \\
\hline Inadequate nurse training & $44.4 \%$ & $70.7 \%$ & $\mathbf{8 3 . 8 \%}$ & $69.5 \%$ & 0.003* \\
\hline Total & $15.0 \%$ & $48.0 \%$ & $73.9 \%$ & $47.6 \%$ & 0.001* \\
\hline \multicolumn{6}{|l|}{ Shortcomings in drug list } \\
\hline Shortage in some drugs & $63.3 \%$ & $72.7 \%$ & $71.1 \%$ & $71.0 \%$ & 0.6 \\
\hline Increase in some drugs & $65.5 \%$ & $48.4 \%$ & $53.1 \%$ & $51.9 \%$ & 0.2 \\
\hline $\begin{array}{l}\text { Increase in drug prescription from } \\
\text { outside drug list }\end{array}$ & $34.5 \%$ & $51.2 \%$ & $63.9 \%$ & $51.0 \%$ & 0.06 \\
\hline Constant drug list & $39,3 \%$ & $46.0 \%$ & $56.8 \%$ & $47.1 \%$ & 0.3 \\
\hline Total & $42.9 \%$ & $41.1 \%$ & $55.2 \%$ & $43.8 \%$ & 0.4 \\
\hline $\begin{array}{l}\text { Total views towards shortcoming in } \\
\text { resources of health system }\end{array}$ & $25.0 \%$ & $53.7 \%$ & $70.6 \%$ & $53.1 \%$ & $0.04 *$ \\
\hline
\end{tabular}

* $\mathrm{P} \leq 0.05$ is considered significant 
Table (3) Views of Respondents towards Management of Health Care Systems by Place of Work

\begin{tabular}{|c|c|c|c|c|c|}
\hline \multirow{2}{*}{$\begin{array}{l}\begin{array}{l}\text { Perspectives to Management of } \\
\text { health systems }\end{array} \\
\text { Planning }\end{array}$} & \multicolumn{4}{|c|}{ Agreement } & \multirow{2}{*}{$\underset{\text { value }}{\mathbf{P}}$} \\
\hline & $\begin{array}{l}\text { PHC } \\
(n=47)\end{array}$ & $\begin{array}{l}\text { SHC } \\
(n=137)\end{array}$ & $\begin{array}{l}\text { Private } \\
(n-41)\end{array}$ & $\begin{array}{c}\text { Total } \\
(\mathbf{n}=\mathbf{2 2 5})\end{array}$ & \\
\hline There is a clear plan to $\mathrm{MOH}$ & $25.9 \%$ & $21.6 \%$ & $6.1 \%$ & $19.3 \%$ & 0.08 \\
\hline There is a plan in each facility & $35.7 \%$ & $25.0 \%$ & $16.7 \%$ & $25.0 \%$ & 0.2 \\
\hline $\begin{array}{l}\text { There is a national specific } \\
\text { targets for health problems }\end{array}$ & $44.4 \%$ & $32.0 \%$ & $26.5 \%$ & $32.8 \%$ & 0.3 \\
\hline $\begin{array}{l}\text { Role of health system is } \\
\text { proactive not reactive }\end{array}$ & $24.1 \%$ & $35.5 \%$ & $32.4 \%$ & $33.2 \%$ & 0.5 \\
\hline $\begin{array}{l}\text { Decision making done on a } \\
\text { scientific base and by a specific } \\
\text { team }\end{array}$ & $42.9 \%$ & $36.3 \%$ & $41.2 \%$ & $38.0 \%$ & 0.7 \\
\hline $\begin{array}{l}\text { No training on organizational } \\
\text { management }\end{array}$ & $\mathbf{5 0 . 0 \%}$ & $48.1 \%$ & $\mathbf{5 7 . 9 \%}$ & $50.3 \%$ & 0.6 \\
\hline $\begin{array}{l}\text { No training on disaster } \\
\text { management }\end{array}$ & $53.3 \%$ & $53.9 \%$ & $\mathbf{5 9 . 5 \%}$ & $54.9 \%$ & 0.8 \\
\hline \multicolumn{6}{|l|}{ Organizational Structure } \\
\hline $\begin{array}{l}\text { There is bias in human resources } \\
\text { recruitment }\end{array}$ & $78.6 \%$ & 72.3\% & $62.5 \%$ & $71.2 \%$ & 0.3 \\
\hline $\begin{array}{l}\text { There is inflation in } \\
\text { organizational structure }\end{array}$ & $55.6 \%$ & $46.1 \%$ & $42.9 \%$ & $46.9 \%$ & 0.6 \\
\hline $\begin{array}{l}\text { There is no staff in some } \\
\text { positions of the organizations }\end{array}$ & $44.8 \%$ & $48.4 \%$ & $45.0 \%$ & $47.1 \%$ & 0.9 \\
\hline $\begin{array}{l}\text { There is staff overload in some } \\
\text { positions of the organizations }\end{array}$ & $41.4 \%$ & $45.8 \%$ & $41.0 \%$ & $44.1 \%$ & 0.8 \\
\hline No job description & $46.4 \%$ & $45.9 \%$ & $64.1 \%$ & $49.7 \%$ & 0.1 \\
\hline $\begin{array}{l}\text { Professional experience is not } \\
\text { important during employment }\end{array}$ & $55.2 \%$ & $62.8 \%$ & $70.0 \%$ & $63.1 \%$ & 0.4 \\
\hline \multicolumn{6}{|l|}{ Clinical training } \\
\hline There is continuous training & $17.2 \%$ & $17.4 \%$ & $22.5 \%$ & $18.4 \%$ & 0.8 \\
\hline $\begin{array}{l}\text { Presence of a policy for } \\
\text { physician license renewal every } \\
3 \text { years }\end{array}$ & $20.0 \%$ & $24.8 \%$ & $23.3 \%$ & $23.8 \%$ & 0.9 \\
\hline 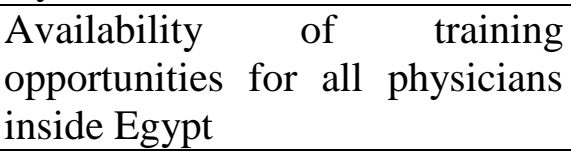 & $3.6 \%$ & $9.8 \%$ & $15.4 \%$ & $10.0 \%$ & 0.3 \\
\hline 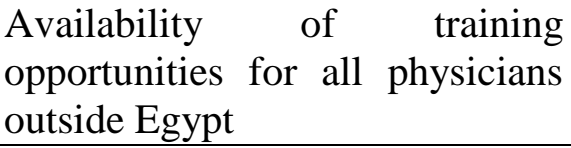 & $26.1 \%$ & $13.8 \%$ & $29.4 \%$ & $8.5 \%$ & 0.01* \\
\hline $\begin{array}{l}\text { Specialist always train the } \\
\text { resident }\end{array}$ & $70.0 \%$ & $53.0 \%$ & $35.0 \%$ & $52.0 \%$ & 0.4 \\
\hline Service delivery is always & $42.9 \%$ & 40.0\% & $28.9 \%$ & $38.2 \%$ & 0.7 \\
\hline
\end{tabular}




\begin{tabular}{|c|c|c|c|c|c|}
\hline $\begin{array}{l}\text { according to scientific basis not } \\
\text { trial and error }\end{array}$ & & & & & \\
\hline \multicolumn{6}{|l|}{ Supervision } \\
\hline There is supervision & $48.3 \%$ & $31.3 \%$ & $26.3 \%$ & $32.8 \%$ & 0.1 \\
\hline Supervision is always supportive & $41.4 \%$ & $27.5 \%$ & $8.3 \%$ & $26.0 \%$ & 0.008 \\
\hline $\begin{array}{l}\text { Supervisors appreciate scientific } \\
\text { background of service providers }\end{array}$ & $24.1 \%$ & $22.7 \%$ & $8.3 \%$ & $20.2 \%$ & 0.1 \\
\hline \multicolumn{6}{|l|}{ Monitoring and Evaluation } \\
\hline $\begin{array}{l}\text { Control on physicians who refer } \\
\text { patients from governmental free } \\
\text { service to their private clinics }\end{array}$ & $14.8 \%$ & $25.4 \%$ & $19.4 \%$ & $22.8 \%$ & 0.4 \\
\hline $\begin{array}{l}\text { Control on infection control } \\
\text { practices }\end{array}$ & $34.5 \%$ & $41.5 \%$ & $21.6 \%$ & $36.8 \%$ & 0.08 \\
\hline Control on drug prescriptions & $32.1 \%$ & $35.8 \%$ & $28.6 \%$ & $33.9 \%$ & 0.7 \\
\hline $\begin{array}{l}\text { Control on misuse of water and } \\
\text { electricity in health facility }\end{array}$ & $39.3 \%$ & $26.2 \%$ & $18.8 \%$ & $26.9 \%$ & 0.2 \\
\hline $\begin{array}{l}\text { Inadequate supervision on drug } \\
\text { distribution }\end{array}$ & $67.9 \%$ & $68.3 \%$ & $60.5 \%$ & $66.7 \%$ & 0.7 \\
\hline $\begin{array}{l}\text { Inadequate supervision } \\
\text { maintenance of equipment }\end{array}$ & $43.3 \%$ & $44.0 \%$ & $23.7 \%$ & $39.9 \%$ & 0.07 \\
\hline \multicolumn{6}{|l|}{ Management Information System } \\
\hline $\begin{array}{l}\text { There is monthly records on } \\
\text { performance indicators }\end{array}$ & $50.0 \%$ & $44.0 \%$ & $30.3 \%$ & $42.4 \%$ & 0.3 \\
\hline $\begin{array}{l}\text { Information system is used in } \\
\text { decision making }\end{array}$ & $29.6 \%$ & $30.6 \%$ & $14.7 \%$ & $27.2 \%$ & 0.2 \\
\hline Decision making is monitored & $33.3 \%$ & $28.3 \%$ & $11.8 \%$ & $25.7 \%$ & 0.09 \\
\hline $\begin{array}{l}\text { Employee of facilities } \\
\text { acknowledge role of information } \\
\text { system }\end{array}$ & 29.65 & 20.45 & $12.1 \%$ & $20.1 \%$ & 0.2 \\
\hline
\end{tabular}

$\mathrm{P} \leq 0.05$ is considered significant 


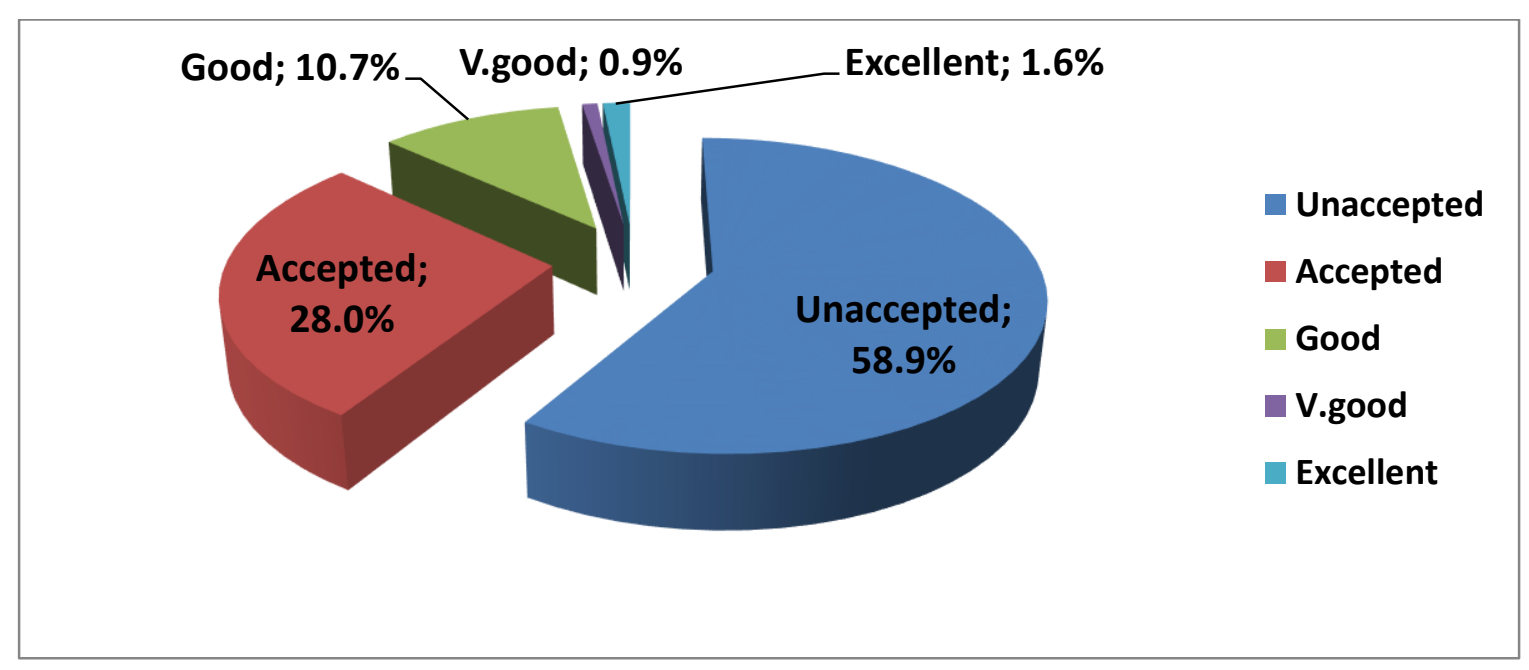

Figure (1) Perspectives of Physicians towards Egyptian Health Status 